\title{
Kinetics of Emulsion Copolymerization of Vinyl Acetate and Vinyl Pivalate
}

\author{
Young-Je KWARK, Won Seok Lyoo, ${ }^{*}{ }^{\dagger}$ and Wan Shik HA \\ Department of Fiber and Polymer Science, Seoul National University, \\ San 56-1, Kwanak-Ku, Seoul 151-742, Korea
}

(Received February 2, 1996)

\begin{abstract}
Vinyl acetate (VAc) and vinyl pivalate (VPi) were homopolymerized and copolymerized by low-temperature redox emulsion polymerization using a manganese chelate as initiator. The polymerization kinetics in these systems were investigated by a mathematical model and estimating the respective kinetic parameters. Among the parameters, the radical entry rate constant, $k_{\mathrm{a}}$, overall rate coefficient for radical desorption, $\bar{k}_{\mathrm{d}}$, and overall termination rate coefficient in the polymer particle, $\bar{k}_{\mathrm{tp}}$, were correlated with each other. However, $k_{\mathrm{a}}, \bar{k}_{\mathrm{d}}$, and rate coefficient for the generation of free radicals from the initiator, $k_{1}$ could not be accurately estimated, since the model was insensitive to these values. The conversion simulated using the estimated parameters showed a reasonable agreement with the experimental results of homopolymerization and copolymerization of VAc and VPi. In a series of experiments of varying initial monomer feed ratio, experimental copolymer composition data more accurately agreed with the simulated values when the partitions of monomers in different phases were considered.

KEY WORDS Vinyl Acetate / Vinyl Pivalate / Emulsion Copolymerization / Polymerization Kinetics / Parameter Estimation/
\end{abstract}

Poly(vinyl alcohol) (PVA) fibers and films have high tensile strength, high tensile modulus, and oxygen barrier properties under dry conditions. ${ }^{1-4}$ However, to have such properties, PVA should possess high syndiotacticity. Nevertheless, PVA obtained from poly(vinyl acetate), the most common precursor of PVA, is almost atactic and has only syndiotactic diad (S-diad) content of about $48-53(\%)$. To enhance the syndiotacticity of PVA, poly(vinyl pivalate) (PVPi) is occasionally used as a precursor of PVA. PVA obtained from PVPi has the highest syndiotacticity among (PVA)s obtained via radical polymerization, and the S-diad content of PVA prepared by low temperature polymerization of vinyl pivalate (VPi) comes to over $60(\%), 5,6$ due to the steric hindrance of $t$-butyl group of VPi. Therefore, we can obtain (PVA)s with various tacticities through the copolymerization of vinyl acetate (VAc) and $\mathrm{VPi}^{7}$ and can examine the relation between physical properties of (PVA)s and their tacticities.

Many investigators have reported various methods for explaining the mechanism of emulsion polymerization. These methods without exception are based on analyzing the time dependence of conversion or particle size distribution (PSD). ${ }^{8-11}$ In addition, there is an approach based on the steady state portion of the conversion-time curves. ${ }^{12,13}$ Recently Asua et al. ${ }^{14}$ and Barandiaran et al. ${ }^{15}$ proposed a new method for parameter estimation in the emulsion polymerization system and de la Cal et $a l .{ }^{16,17}$ estimated the reactivity ratios and kinetic constants in an emulsion copolymerization system by using Asua's method. This method is based on an algorithm for parameter estimation in a differential equation and uses the evolution of monomer conversion in chemically initiated seeded emulsion polymerization. The advantages of the method are: (1) time dependence of conversion is more sensitive than that of PSD analysis to the values of the parameters; (2) experiments can be carried out easily with standard laboratory equipment; (3) the model involves the fundamental parameters of the process; (4) estimation algorithm uses all experimental data obtained under different conditions; and (5) algorithm allows estimation of all the parameters of the model.

In this work, VAc and VPi were homopolymerized and copolymerized by low-temperature redox emulsion polymerization, and the polymerization kinetics in this system were investigated by Asua's method. A mathematical model was developed and parameters were estimated by non-linear regression using the LevenbergMarquardt method. ${ }^{18}$ Using these estimated values, copolymerization results with the monomer feed ratio were simulated and compared with experimental data.

\section{MATHEMATICAL MODELING}

The following assumptions were made in the present model: (1) from a kinetic point of view, the whole population of polymer particles could be represented by a monodisperse population of particles; (2) polymer particles could be produced by homogeneous nucleation; (3) the concentrations of monomers in different phases were at equilibrium and had constant values; (4) the pseudo-steady state for the radicals in the aqueous phase was applied; (5) initiator radicals were produced in the aqueous phase only.

\section{Material Balance for Monomers}

$$
\begin{aligned}
\frac{\mathrm{d} x_{\mathrm{A}}}{\mathrm{d} t}= & \left(k_{p_{\mathrm{AA}}} P_{\mathrm{A}}^{p}+k_{p_{\mathrm{BA}}} P_{\mathrm{B}}^{p}\right)[\mathrm{A}]_{p} \frac{\bar{n} N_{\mathrm{T}}}{M_{\mathrm{A} 0} N_{\mathrm{A}}} \\
& +\left(k_{p_{\mathrm{AA}}} P_{\mathrm{A}}^{\mathrm{aq}}+k_{p_{\mathrm{BA}}} P_{\mathrm{B}}^{\mathrm{aq}}\right)[\mathrm{A}]_{\mathrm{aq}} \frac{[\mathrm{R}]_{\mathrm{aq}}}{M_{\mathrm{A} 0} \varphi_{\mathrm{w}}^{\mathrm{aq}}}
\end{aligned}
$$

\footnotetext{
* Present address: Division of Polymer Researches, Korea Institute of Science and Technology, P.O. Box 131, Cheongryang, Seoul, Korea.
}

† To whom all correspondence should be addressed. 


$$
\begin{aligned}
\frac{\mathrm{d} x_{\mathrm{B}}}{\mathrm{d} t}= & \left(k_{p_{\mathrm{AB}}} P_{\mathrm{A}}^{p}+k_{p_{\mathrm{BB}}} P_{\mathrm{B}}^{p}\right)[\mathrm{B}]_{p} \frac{\bar{n} N_{\mathrm{T}}}{M_{\mathrm{B} 0} N_{\mathrm{A}}} \\
& +\left(k_{p_{\mathrm{AB}}} P_{\mathrm{A}}^{\mathrm{aq}}+k_{p_{\mathrm{BB}}} P_{\mathrm{B}}^{\mathrm{aq}}\right)[\mathrm{B}]_{\mathrm{aq}} \frac{[\mathrm{R}]_{\mathrm{aq}}}{M_{\mathrm{B} 0} \varphi_{\mathrm{w}}^{\mathrm{aq}}}
\end{aligned}
$$

where $x_{\mathrm{i}}$ is the conversion of monomer $i, k_{p_{i j}}$ propagation rate constant, $[i]_{j}$ concentration of monomer $i$ in the $j$ phase, $[\mathrm{R}]_{\mathrm{aq}}$ concentration of free radicals in the aqueous phase, $M_{\mathrm{A} 0}$ number of moles of monomer $i$ initially charged into the reactor, $N_{\mathrm{T}}$ total number of polymer particles per $\mathrm{cm}^{3}$ of water, $\bar{n}$ average number of radicals per particle, $\varphi_{\mathrm{w}}^{\mathrm{aq}}$ volume fraction of water in the aqueous phase, and $P_{i}^{j}$-time averaged probability of finding a radical chain with ultimate unit of type $i$ in the $j$ phase. These probabilities are given by:

$$
P_{\mathrm{A}}^{j}=\frac{k_{p_{\mathrm{BA}}}[\mathrm{A}]_{j}}{k_{p_{\mathrm{BA}}}[\mathrm{A}]_{j}+k_{p_{\mathrm{AB}}}[\mathrm{B}]_{j}}, \text { and } P_{\mathrm{B}}^{j}=1-P_{\mathrm{A}}^{j}
$$

To simplify the experiment, the total material balance instead of fractional material balance was used.

$$
\frac{\mathrm{d} x_{\mathrm{T}}}{\mathrm{d} t}=\frac{1}{\left(M_{\mathrm{A} 0}+M_{\mathrm{B} 0}\right)}\left\{\left(\frac{\mathrm{d} x_{\mathrm{A}}}{\mathrm{d} t}\right) M_{\mathrm{A} 0}+\left(\frac{\mathrm{d} x_{\mathrm{B}}}{\mathrm{d} t}\right) M_{\mathrm{B} 0}\right\}
$$

\section{Population Balance for Particles Containing i Radicals}

If polymerization is carried out at a surfactant concentration below the critical micelle concentration, heterogeneous nucleation can be neglected in the model. Although the presence of seed reduces the extent of the secondary nucleation, homogeneous nucleation cannot be avoided for a monomer having significant solubility in water. ${ }^{19}$ The rate of formation of new particles by homogeneous nucleation is that of oligomers having a length greater than the critical value. Even of this critical value is different for the oligomers from the initiator radicals, in this paper, a single value was used for both types of radicals. The rate of formation of new particles is given by:

$$
\begin{aligned}
\frac{\mathrm{d} N_{\mathrm{T}}}{\mathrm{d} t}=\left\{\left(k_{p_{\mathrm{AA}}} P_{\mathrm{A}}^{\mathrm{aq}}+k_{p_{\mathrm{B} \mathrm{A}}} P_{\mathrm{B}}^{\mathrm{aq}}\right)[\mathrm{A}]_{\mathrm{aq}}\right. \\
\left.+\left(k_{p_{\mathrm{AB}}} P_{\mathrm{A}}^{\mathrm{aq}}+k_{p_{\mathrm{BB}}} P_{\mathrm{B}}^{\mathrm{aq}}\right)[\mathrm{B}]_{\mathrm{aq}}\right\} \frac{\left[\mathrm{R}_{j_{\mathrm{crit}}}\right] N_{\mathrm{A}}}{\varphi_{\mathrm{w}}^{\mathrm{aq}}}
\end{aligned}
$$

where $\left[R_{j_{\text {crit }}}\right]$ is the concentration of oligoradicals with a critical length in the aqueous phase. The population balance for the particles containing $i$ radicals is given by:

$$
\begin{aligned}
\frac{\mathrm{d} N_{i}}{\mathrm{~d} t}= & k_{\mathrm{a}}[\mathrm{R}]_{\mathrm{aq}}\left(N_{i-1}-N_{i}\right)+\bar{k}_{\mathrm{d}}\left\{(i+1) N_{i+1}-i N_{i}\right\} \\
& +\frac{\bar{k}_{i \mathrm{p}}}{v_{\mathrm{p}} N_{\mathrm{A}}}\left\{(i+2)(i+1) N_{i+2}-i(i-1) N_{i}\right\}
\end{aligned}
$$$$
\text { for } i \geq 2
$$

$$
\frac{\mathrm{d} N_{0}}{\mathrm{~d} t}=-k_{\mathrm{a}}[\mathrm{R}]_{\mathrm{aq}} N_{\mathrm{O}}+\bar{k}_{\mathrm{d}} N_{1}+\frac{\bar{k}_{\mathrm{tp}}}{v_{\mathrm{p}} N_{\mathrm{A}}} 2 N_{2}
$$

$$
\begin{aligned}
\frac{\mathrm{d} N_{1}}{\mathrm{~d} t}= & \left\{\left(k_{p_{\mathrm{AA}}} P_{\mathrm{A}}^{\mathrm{aq}}+k_{p_{\mathrm{BA}}} P_{\mathrm{B}}^{\mathrm{aq}}\right)[\mathrm{A}]_{\mathrm{aq}}\right. \\
& \left.+\left(k_{p_{\mathrm{AB}}} P_{\mathrm{A}}^{\mathrm{aq}}+k_{p_{\mathrm{BB}}} P_{\mathrm{B}}^{\mathrm{aq}}\right)[\mathrm{B}]_{\mathrm{aq}}\right\} \frac{\left[\mathrm{R}_{j_{\mathrm{crit}}}\right] N_{\mathrm{A}}}{\varphi_{\mathrm{w}}^{\mathrm{aq}}} \\
& +k_{\mathrm{a}}[\mathrm{R}]_{\mathrm{aq}}\left(N_{0}-N_{1}\right)+\bar{k}_{\mathrm{d}}\left(2 N_{2}-N_{1}\right)+\frac{\bar{k}_{\mathrm{tp}}}{v_{\mathrm{p}} N_{\mathrm{A}}} 6 N_{3}
\end{aligned}
$$

where $k_{\mathrm{a}}$ is the radical entry rate coefficient, $\bar{k}_{\mathrm{d}}$ overall rate coefficient for radical desorption, $\bar{k}_{\mathrm{tp}}$ overall termination rate coefficient in the polymer particle, and $v_{\mathrm{p}}$ volume of a monomer swollen polymer particle.

In practice, the series has to be truncated at a large enough number of radicals $(i=m)$.

$$
\begin{aligned}
\frac{\mathrm{d} N_{m}}{\mathrm{~d} t}= & k_{\mathrm{a}}[\mathrm{R}]_{\mathrm{aq}}\left(N_{m-1}-N_{m}\right) \\
& -\bar{k}_{\mathrm{d}} m N_{m}-\frac{\bar{k}_{\mathrm{tp}}}{v_{\mathrm{p}} N_{\mathrm{A}}} m(m-1) N_{m} \\
\frac{\mathrm{d} N_{m-1}}{\mathrm{~d} t}= & k_{\mathrm{a}}[\mathrm{R}]_{\mathrm{aq}}\left(N_{m-2}-N_{m-1}+N_{m}\right) \\
& +\bar{k}_{\mathrm{d}}\left\{m N_{m}-(m-1) N_{m-1}\right\} \\
& \quad-\frac{\bar{k}_{\mathrm{tp}}}{v_{\mathrm{p}} N_{\mathrm{A}}}(m-1)(m-2) N_{m-1}
\end{aligned}
$$

where $m$ is the maximum number of radicals that can coexist in a polymer particle without instantaneous termination reaction.

Material Balance for Free Radicals in the Aqueous Phase

$$
\begin{aligned}
\frac{\mathrm{d}\left[\mathrm{R}_{i}\right]}{\mathrm{d} t}= & \left\{\left(k_{p_{\mathrm{AA}}} P_{\mathrm{A}}^{\mathrm{aq}}+k_{p_{\mathrm{BA}}} P_{\mathrm{B}}^{\mathrm{aq}}\right)[\mathrm{A}]_{\mathrm{aq}}\right. \\
& \left.+\left(k_{p_{\mathrm{AB}}} P_{\mathrm{A}}^{\mathrm{aq}}+k_{p_{\mathrm{BB}}} P_{\mathrm{B}}^{\mathrm{aq}}\right)[\mathrm{B}]_{\mathrm{aq}}\right\}\left(\left[\mathrm{R}_{i-1}\right]-\left[\mathrm{R}_{i}\right]\right) \\
& -k_{\mathrm{a}} \frac{\left[\mathrm{R}_{i}\right] \varphi_{\mathrm{w}}^{\mathrm{aq}}}{N_{\mathrm{A}}}-\bar{k}_{\mathrm{tw}}\left[\mathrm{R}_{i}\right][\mathrm{R}]_{\mathrm{aq}} \\
\frac{\mathrm{d}\left[\mathrm{R}_{1}\right]}{\mathrm{d} t}= & k_{\mathrm{l}}[\mathrm{I}]+\bar{k}_{\mathrm{d}} \frac{\bar{n} N_{\mathrm{T}}}{N_{\mathrm{A}}}-\left\{\left(k_{p_{\mathrm{AA}}} P_{\mathrm{A}}^{\mathrm{aq}}+k_{p_{\mathrm{BA}}} P_{\mathrm{B}}^{\mathrm{aq}}\right)[\mathrm{A}]_{\mathrm{aq}}\right. \\
& \left.+\left(k_{p_{\mathrm{AB}}} P_{\mathrm{A}}^{\mathrm{aq}}+k_{p_{\mathrm{BB}}} P_{\mathrm{B}}^{\mathrm{aq}}\right)[\mathrm{B}]_{\mathrm{aq}}\right\}\left[R_{1}\right] \\
& -k_{\mathrm{a}} \frac{\left[\mathrm{R}_{1}\right] \varphi_{\mathrm{w}}^{\mathrm{aq}}}{N_{\mathrm{A}}}-\bar{k}_{\mathrm{tw}}\left[\mathrm{R}_{1}\right][R]_{\mathrm{aq}}
\end{aligned}
$$

where $k_{1}$ is the rate coefficient in the generation of free radicals from the initiator including all other effects except initiator concentration, $[\mathrm{I}]$ concentration of the initiator initially charged, and $\bar{k}_{\mathrm{tw}}$ average termination rate coefficient in the aqueous phase.

Taking into account the pseudo-steady state assumption, we can rearrange eq 11 and 12 to obtain: 


$$
\begin{gathered}
{\left[\mathrm{R}_{i}\right]=\frac{\left(k_{1}[\mathrm{I}]+\bar{k}_{\mathrm{d}} \frac{\bar{n} N_{\mathrm{T}} \varphi_{\mathrm{w}}^{\mathrm{aq}}}{N_{\mathrm{A}}}\right)}{\left(k_{p_{\mathrm{AA}}} P_{\mathrm{A}}^{\mathrm{aq}}+k_{p_{\mathrm{BA}}} P_{\mathrm{B}}^{\mathrm{aq}}\right)[\mathrm{A}]_{\mathrm{aq}}+\left(k_{p_{\mathrm{AB}}} P_{\mathrm{A}}^{\mathrm{aq}}+k_{p_{\mathrm{BB}}} P_{\mathrm{B}}^{\mathrm{aq}}\right)[\mathrm{B}]_{\mathrm{aq}}} \alpha^{i}} \\
\alpha^{i}=\frac{\left(k_{p_{\mathrm{AA}}} P_{\mathrm{A}}^{\mathrm{aq}}+k_{p_{\mathrm{BA}}} P_{\mathrm{B}}^{\mathrm{aq}}\right)[\mathrm{A}]_{\mathrm{aq}}+\left(k_{p_{\mathrm{AB}}} P_{\mathrm{A}}^{\mathrm{aq}}+k_{p_{\mathrm{BB}}} P_{\mathrm{B}}^{\mathrm{aq}}\right)[\mathrm{B}]_{\mathrm{aq}}}{\left(k_{p_{\mathrm{AA}}} P_{\mathrm{A}}^{\mathrm{aq}}+k_{p_{\mathrm{BA}}} P_{\mathrm{B}}^{\mathrm{aq}}\right)[\mathrm{A}]_{\mathrm{aq}}+\left(k_{p_{\mathrm{AB}}} P_{\mathrm{A}}^{\mathrm{aq}}+k_{p_{\mathrm{BB}}} P_{\mathrm{B}}^{\mathrm{aq}}\right)[\mathrm{B}]_{\mathrm{aq}}+\bar{k}_{\mathrm{tw}}[\mathrm{R}]_{\mathrm{aq}}+k_{\mathrm{a}} \frac{\varphi_{\mathrm{w}}^{\mathrm{aq}}}{N_{\mathrm{A}}}}
\end{gathered}
$$

For a system chemically initiated, the initial conditions are

$$
t=0, \quad x_{\mathrm{T}}=0, \quad N_{i}=0(i \neq 0), \quad \text { and } \quad N_{0}=N_{\mathrm{T} 0}
$$

where $N_{\text {T0 }}$ is the number of seed particles initially charged.

Equations 1-15 constitute a system of initial-value stiff differential equations containing nine unknown parameters, $k_{p_{\mathrm{AA}}}, k_{p_{\mathrm{BB}}}, k_{p_{\mathrm{AB}}}, k_{p_{\mathrm{BA}}}, k_{\mathrm{a}}, \bar{k}_{\mathrm{d}}, k_{\mathrm{l}}, \bar{k}_{\mathrm{tp}}$, and $\bar{k}_{\mathrm{tw}}$. However, Asua et al. ${ }^{14}$ demonstrated that $k_{\mathrm{a}}$ and $\bar{k}_{\mathrm{tw}}$ are correlated. Hence they cannot be unambiguously determined unless some independent measurement of the concentrations of radicals in the aqueous phase is available; the value of $\bar{k}_{\mathrm{tw}}$ was not estimated in this work.

De la Cal et al. ${ }^{16}$ demonstrated that if the partition of the monomers between the different phases is considered, the reactivity ratios obtained from homogeneous copolymerization experiments are the same as those obtained from batch emulsion copolymerization. Accordingly, the values reported in the literature were used in this work. The homopolymerization rate constants can be expressed as follows:

$$
k_{p_{\mathrm{AA}}}=r_{\mathrm{A}} \times k_{p_{\mathrm{AB}}}, \quad \text { and } \quad k_{p_{\mathrm{BB}}}=r_{\mathrm{B}} \times k_{p_{\mathrm{BA}}}
$$

where $r$ is the reactivity ratio. Therefore, $k_{p_{\mathrm{AB}}}, k_{p_{\mathrm{BA}}}, k_{\mathrm{a}}$, $\bar{k}_{\mathrm{d}}, k_{\mathrm{l}}$, and $\bar{k}_{\mathrm{tp}}$ are the adjustable parameters of the model.

Parameter estimation involves the choice of an object function to be minimized. In this work, the residual sum of squares was chosen:

Sum of squares of difference (SD) $=\sum_{j=1}^{M} \sum_{i=1}^{G_{j}}\left(x_{\mathrm{T}, \mathrm{e}}-x_{\mathrm{T}, \mathrm{c}}^{h}\right)_{i, j}^{2}$

where $M$ is the number of experiments, $G_{j}$ number of experiments in an experiment $j, x_{\mathrm{T}, \mathrm{e}}$ total conversion measured, and $x_{\mathrm{T}, \mathrm{c}}^{h}$ model prediction using the set of parameters $h$.

\section{EXPERIMENTAL}

\section{Materials}

VAc and VPi were purified by washing with an aqueous solution of $\mathrm{NaHSO}_{3}$, drying over anhydrous $\mathrm{CaCl}_{2}$, and distilling under reduced pressure of $\mathrm{N}_{2}$. Polyoxyethylene nonyl phenyl ether sodium sulfate (LWZ ${ }^{\circledR}$ : Kao Co.) was used as the emulsifier and the other materials were used without further purification. The seed particles were prepared via batch process at $70^{\circ} \mathrm{C}$ for 2 hours using distilled-deionized water (DDI-water, $297 \mathrm{ml}$ ), potassium peroxodisulfate $\left(3.74 \times 10^{-5} \mathrm{~mol} \mathrm{~cm}^{-3}\right.$ of water $)$, and
Table I. VAc homopolymerization conditions

$\begin{array}{lc}\text { DDI-water } & 50 \mathrm{ml} \\ \text { Vinyl acetate } & 2.32 \times 10^{-3} \mathrm{~mol} \mathrm{~cm}^{-3} \text { of water } \\ \text { LWZ } & 5 \times 10^{-3} \mathrm{~g} \mathrm{~cm}^{-3} \text { of water } \\ \text { Citric acid } & 1.25 \times 10^{-5} \mathrm{~mol} \mathrm{~cm}^{-3} \text { of water } \\ \text { Manganic(II) acetylacetonate } & 7 \times 10^{-5} \mathrm{~mol} \mathrm{~cm}^{-3} \text { of water } \\ & 5 \times 10^{-5} \\ & 3 \times 10^{-5} \\ \text { Seed latex } & 9 \times 10^{11} \text { particles cm } \\ & 6 \times 10^{11} \\ & 3 \times 10^{11}\end{array}$

monomer $\left(9 \times 10^{-4} \mathrm{~mol} \mathrm{~cm}^{-3}\right.$ of water $)$. The polymer latex was dialyzed and used as seed particles. The number of seed particles was determined from the polymer concentration in the latex and the diameter of particles obtained by measuring dynamic light scattering on a Malvern Zetasizer 3.

\section{Homopolymerization of $V A c$}

The homopolymerization of VAc was carried out in a $200 \mathrm{ml}$ glass vessel equipped with a sampling device and a thermostat. The polymerization conditions are summarized in Table I. The polymerization was performed varying the initiator concentration and the number of seed particles initially charged. DDI-water, citric acid, LWZ, and seed latex were charged into the reactor and bubbled with $\mathrm{N}_{2}$ to remove the oxygen from the reactor, which was composed of a double wall and thermally controlled at $10^{\circ} \mathrm{C}$. Manganic(II) acetylacetonate (Aldrich Co.) was dissolved in the degassed monomer and this was added to the reactor. A sample of the reaction mixture was withdrawn through a sampling cock attached to the bottom of the reactor at appropriate intervals; the latex withdrawn was shortstopped by adding the monomethyl ether of hydroquinone solution and dried in a vacuum oven at $60^{\circ} \mathrm{C}$ for the determination of conversion.

\section{Copolymerization of $V A c$ and $V P i$}

To determine kinetic parameters, batch copolymerizations were carried out varying the initiator concentration and number of seed particles initially charged, while the initial feed monomer mole ratio was kept constant, $5 / 5$. The detailed polymerization conditions are summarized in Table II.

Another series of copolymerizations was also carried out varying only the initial monomer feed $(\mathrm{VAc} / \mathrm{VPi}=9 / 1$, $7 / 3,5 / 5,3 / 7$, and $1 / 9$ ), all other conditions were kept constant: water, $50 \mathrm{ml}$; LWZ, $5 \times 10^{-3} \mathrm{~g} \mathrm{~cm}^{-3}$ of water; manganic acetylacetonate, $7 \times 10^{-6} \mathrm{~mol} \mathrm{~cm}{ }^{-3}$ of water; citric acid, $5 \times 10^{-5} \mathrm{~mol} \mathrm{~cm}^{-3}$ of water; total monomers 
Table II. VAc-VPi copolymerization conditions

\begin{tabular}{lc}
\hline DDI-water & $50 \mathrm{ml}$ \\
Vinyl acetate & $7.5 \times 10^{-4} \mathrm{~mol} \mathrm{~cm}^{-3}$ of water \\
Vinyl pivalate & $7.5 \times 10^{-4} \mathrm{~mol} \mathrm{~cm}^{-3}$ of water \\
LWZ & $5 \times 10^{-3} \mathrm{~g} \mathrm{~cm}^{-3}$ of water \\
Citric aicd & $5 \times 10^{-5} \mathrm{~mol} \mathrm{~cm}^{-3}$ of water \\
Manganic(II) acetylacetonate & $1 \times 10^{-5} \mathrm{~mol} \mathrm{~cm}^{-3}$ of water \\
& $7 \times 10^{-6}$ \\
& $3 \times 10^{-6}$ \\
Seed latex & $6.0 \times 10^{11} \mathrm{particles} \mathrm{cm}^{-3}$ of water \\
& $3.0 \times 10^{11}$ \\
& $1.5 \times 10^{11}$ \\
& $8.0 \times 10^{10}$
\end{tabular}

Table III. Values of parameters used in simulation of the VAc-MA system ${ }^{16}$

\begin{tabular}{lrlr}
\hline$k_{p_{\mathrm{AA}}}$ & $0.230 \times 10^{7} \mathrm{~cm}^{3}(\mathrm{~mol} \mathrm{~s})^{-1}$ & $p_{p_{\mathrm{AB}}}$ & $0.230 \times 10^{8} \mathrm{~cm}^{3}(\mathrm{~mol} \mathrm{~s})^{-1}$ \\
$k_{p_{\mathrm{BB}}}$ & $0.209 \times 10^{7} \mathrm{~cm}^{3}(\mathrm{~mol} \mathrm{~s})^{-1}$ & $k_{p_{\mathrm{BA}}}$ & $0.232 \times 10^{6} \mathrm{~cm}^{3}(\mathrm{~mol} \mathrm{~s})^{-1}$ \\
$k_{t_{\mathrm{AA}}}$ & $0.290 \times 10^{11} \mathrm{~cm}^{3}\left(\mathrm{~mol} \mathrm{~s}^{-1}\right.$ & $k_{t_{\mathrm{BB}}}$ & $0.950 \times 10^{10} \mathrm{~cm}^{3}(\mathrm{~mol} \mathrm{~s})^{-1}$ \\
$k_{\mathrm{a}}$ & $0.8 \times 10^{10} \mathrm{~cm}^{3}\left(\mathrm{~cm}^{3}\right)^{-1}$ & $k_{\mathrm{d}}$ & $0.11 \times 10^{-1} 1 \mathrm{~s}^{-1}$ \\
$k_{1}$ & $0.1 \times 10^{-5} 1 \mathrm{~s}^{-1}$ & $m$ & 3 \\
$j_{\text {crit }}$ & $60^{\mathrm{a}}$ & $v_{\mathrm{p}}$ & $1.3 \times 10^{-15} \mathrm{~cm}^{3}$ \\
$m_{\text {Aqp }}$ & 28 & $m_{\text {Aqd }}$ & 42.5 \\
$m_{\text {Bqp }}$ & 14 & $m_{\mathrm{Bqd}}$ & 20 \\
$m_{\text {wqd }}$ & $0.2 \times 10^{-2}$ & & \\
\hline
\end{tabular}

${ }^{\text {a }}$ From ref 19.

Table IV. Estimated $k_{\mathrm{a}}, \bar{k}_{\mathrm{d}}$, and $\bar{k}_{\mathrm{t}}$ in the VAc-MA system

\begin{tabular}{|c|c|c|c|c|c|c|}
\hline \multicolumn{3}{|c|}{ Initial guess } & \multicolumn{3}{|c|}{ Estimated value } & \multirow{2}{*}{$\mathrm{SD}^{\mathrm{a}}$} \\
\hline$k_{\mathrm{a}} \times 10^{-10}$ & $\bar{k}_{\mathrm{d}} \times 10^{1}$ & $\bar{k}_{\mathrm{tp}} \times 10^{-10}$ & $k_{\mathrm{a}} \times 10^{-10}$ & $\bar{k}_{\mathrm{d}} \times 10^{1}$ & $\bar{k}_{\mathrm{tp}} \times 10^{-10}$ & \\
\hline 0.5 & 0.1 & 0.5 & 0.4999 & 0.0909 & 0.4948 & $8.11 \times 10^{-5}$ \\
\hline 0.1 & 0.7 & 0.3 & 0.2514 & 0.0521 & 0.2578 & $9.10 \times 10^{-5}$ \\
\hline
\end{tabular}

${ }^{a} \mathrm{SD}$, sum of squares of differences.

$1.5 \mathrm{~mol} \mathrm{~cm} \mathrm{~cm}^{-3}$ of water.

The copolymerization method was the same as that in the VAc homopolymerization. The conversion was determined by gravimetry and copolymer composition was obtained by ${ }^{13} \mathrm{C}$ NMR spectroscopy (Bruker AC-200, $50.13 \mathrm{MHz}$ ) after precipitation and washing of the copolymers.

\section{RESULTS AND DISCUSSION}

\section{Check of Approach}

The approach to parameter estimation had to be checked prior to application to experimental data. Therefore, the data were generated by simulation using arbitrary but reasonable values of the rate coefficients and then the approach was applied to the generated data in an attempt to estimate these rate coefficients

The interval II of the seeded emulsion copolymerization of VAc $(A)$ and methyl acrylate (MA) $(B)$ was simulated by integrating eq 1-16 using the Gear algorithm. ${ }^{20}$ The values of the parameters used in the simulation are given in Table III.

The concentrations of the monomers in the different phases were calculated using the partition coefficients given in Table III, which were defined as follows:

$$
\begin{aligned}
& m_{i j k} \frac{[i]_{k}}{[i]_{j}} \quad i=\operatorname{VAc}(A), \operatorname{MA}(B), \text { and water }(w) \\
& j, k=\text { aqueous phase }(q) \text {, polymer particle }(p), \\
& \text { and monomer droplet }(d)
\end{aligned}
$$

where $m_{i j k}$ is the partition coefficient of species $i$ between $j$ and $k$ phases.

The average termination rate coefficients in the polymer particles and aqueous phase were calculated as follows:

$$
\begin{aligned}
& \bar{k}_{\mathrm{t} \mathrm{p}}=k_{\mathrm{t}_{\mathrm{AA}}} P_{\mathrm{A}}^{\mathrm{p}^{2}}+2 k_{\mathrm{t}_{\mathrm{AB}}} P_{\mathrm{A}}^{\mathrm{p}} P_{\mathrm{B}}^{\mathrm{p}}+k_{\mathrm{t}_{\mathrm{BB}}} P_{\mathrm{B}}^{\mathrm{p}^{2}} \\
& \bar{k}_{\mathrm{t}_{\mathrm{w}}}=k_{\mathrm{t}_{\mathrm{AA}}} P_{\mathrm{A}}^{\mathrm{aq}{ }^{2}}+2 k_{\mathrm{t}_{\mathrm{AB}}} P_{\mathrm{A}}^{\mathrm{aq}} P_{\mathrm{B}}^{\mathrm{aq}}+k_{t_{\mathrm{BB}}} P_{\mathrm{B}}^{\mathrm{aq}}{ }^{2} \\
& k_{\mathrm{t}_{\mathrm{AB}}}=\left(k_{t_{\mathrm{AA}}} \cdot k_{t_{\mathrm{BB}}}\right)^{1 / 2}
\end{aligned}
$$

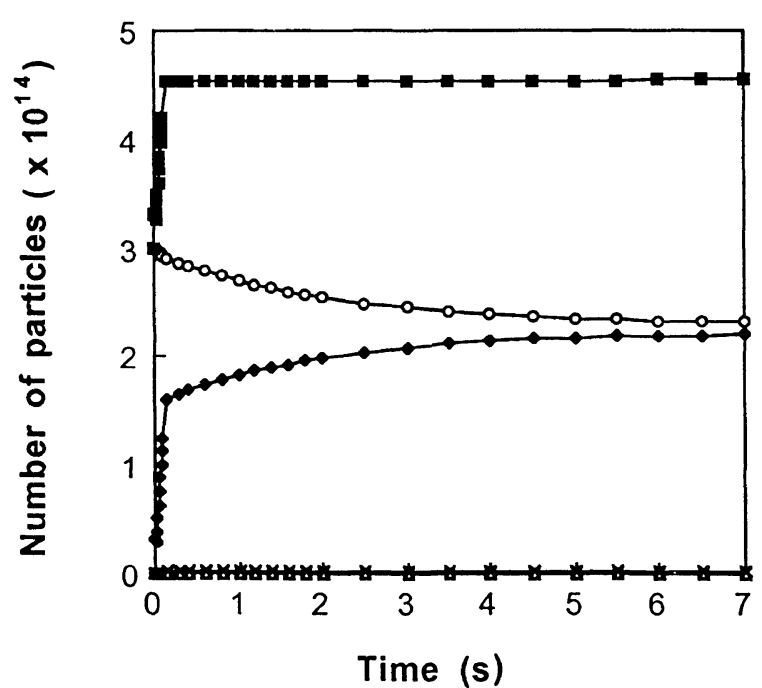

Figure 1. Change in number of particles containing $i$ radicals $\left(N_{i}\right)$ at initial stage $\left(N_{\mathrm{T} 0}=3 \times 10^{11}\right.$ particles $\mathrm{cm}^{-3}$ of water $)-\mathbf{-}-, N_{\mathrm{T}}$; $-\mathrm{-}, N_{0} ;-\mathbf{-}-, N_{1} ;-\backsim-N_{2} ;-\triangle-, N_{3}$.

Each set of "experiments" including nine kinetic runs with a variation in the concentration of the initiator and seed particle numbers. The three seed particle numbers $\left(N_{\mathrm{T} 0}=9 \times 10^{11}, 6 \times 10^{11}\right.$, and $3 \times 10^{11}$ particles $\mathrm{cm}^{-3}$ of water) and the three initiator concentrations $([\mathrm{I}]=2 \times$ $10^{-5}, 1 \times 10^{-5}$, and $2 \times 10^{-6} \mathrm{~mol} \mathrm{~cm}^{-3}$ of water) were used. As a final approximation, the constancy of the rate parameters was assumed over the whole range of experimental conditions.

Table IV shows the effect of different initial guesses on the estimated parameters, $k_{\mathrm{a}}, \bar{k}_{\mathrm{d}}$, and $\bar{k}_{\mathrm{tp}}$. It can be seen from Table IV that the different values of $k_{\mathrm{a}}, \bar{k}_{\mathrm{d}}$, and $\bar{k}_{\mathrm{tp}}$ results in fit of the data, which are indistinguishable from each other regarding the residual sum of squares, suggesting either the presence of multiple minima in the objective function or a correlation between these parameters.

Figure 1 shows that the number of particles containing $i$ radicals reaches a steady value at a very early stage, 
Table V. Estimated $k_{\mathrm{a}}, \bar{k}_{\mathrm{d}}, k_{\mathrm{l}}$, and $k_{p_{\mathrm{BA}}}$ in the VAc-MA system

\begin{tabular}{|c|c|c|c|c|c|c|c|c|}
\hline \multicolumn{4}{|c|}{ Initial guess } & \multicolumn{4}{|c|}{ Estimated value } & \multirow{2}{*}{$\mathrm{SD}^{\mathrm{a}}$} \\
\hline$k_{\mathrm{a}} \times 10^{-10}$ & $\bar{k}_{\mathrm{d}} \times 10^{1}$ & $k_{1} \times 10^{5}$ & $k_{p_{\mathrm{BA}}} \times 10^{-6}$ & $k_{\mathrm{a}} \times 10^{-10}$ & $\bar{k}_{\mathrm{d}} \times 10^{1}$ & $k_{1} \times 10^{5}$ & $k_{p_{\mathrm{BA}}} \times 10^{-6}$ & \\
\hline 0.5 & 0.5 & 0.5 & 0.5 & 0.6917 & 0.1267 & 0.1037 & 0.2330 & $5.20 \times 10^{-5}$ \\
\hline 0.5 & 0.1 & 0.3 & 0.3 & 0.6270 & 0.1851 & 0.0846 & 0.2343 & $2.03 \times 10^{-4}$ \\
\hline 0.1 & 0.7 & 0.5 & 0.1 & 1.3059 & 0.0878 & 0.1040 & 0.2290 & $1.68 \times 10^{-5}$ \\
\hline
\end{tabular}

${ }^{\text {a }} \mathrm{SD}$, sum of squares of differences.

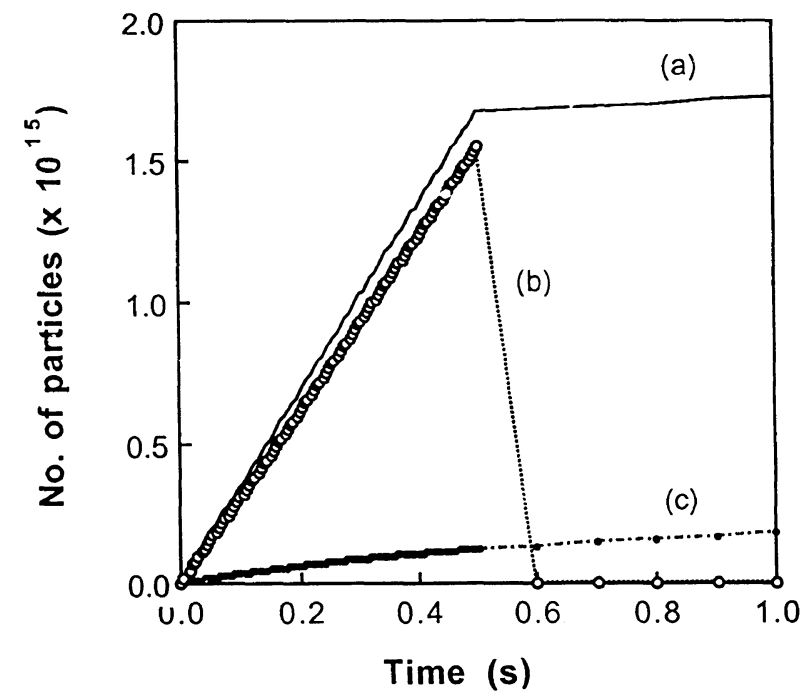

Figure 2. Formation of particles containing one radical $\left(N_{1}\right.$ particles $)$ at initial stage: (a) total number of $N_{1}$ particles; (b) number of $N_{1}$ particles formed by homogeneous nucleation; (c) number of $N_{1}$ particles formed by radical absorption of $N_{0}$ particles.

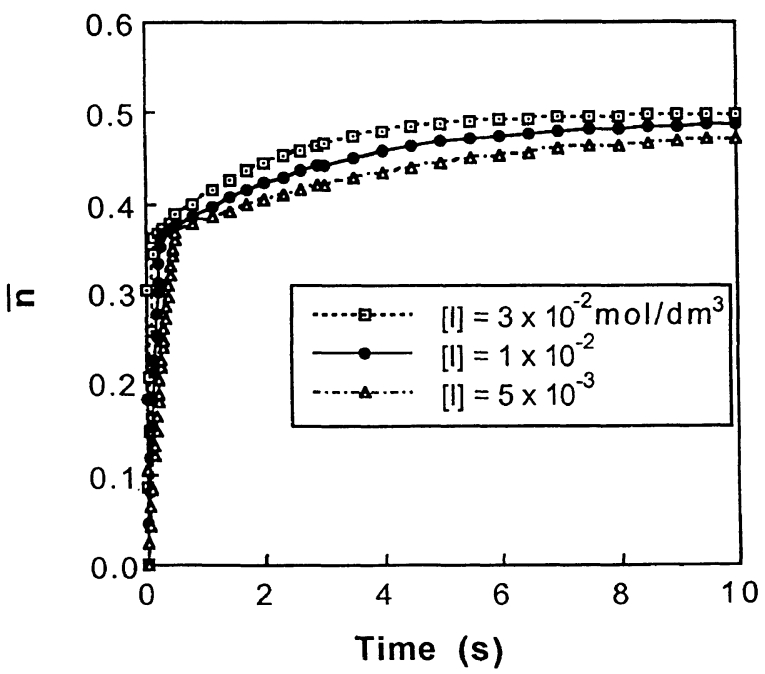

Figure 3. Change in average number of radicals per particle $(\bar{n})$ at initial stage $\left(N_{\mathrm{T} 0}=9 \times 10^{11}\right.$ particles $\mathrm{cm}^{-3}$ of water $) .---\square--,[\mathrm{I}]=$ $3 \times 10^{-2} \mathrm{moldm}^{-3} ; \quad-\quad-,[\mathrm{I}]=1 \times 10^{-2} \mathrm{~mol} \mathrm{dm}^{-3} ; \quad---\mathbf{A}_{-}-$, $^{-}$ $[\mathrm{I}]=5 \times 10^{-3} \mathrm{~mol} \mathrm{dm}^{-3}$.

and it is thought that these values are constant throughout the whole time range. Therefore, the parameters, $k_{\mathrm{a}}$, $\overline{k_{\mathrm{d}}}$, and $\bar{k}_{\mathrm{tp}}$ could be correlated to each other from eq 6 by assuming the pseudo-steady state for $[\mathrm{R}]_{\mathrm{aq}}$. However, this implies that $k_{\mathrm{a}}, \bar{k}_{\mathrm{d}}$, and $\bar{k}_{\mathrm{tp}}$ cannot be unambiguously determined at the same time, and in this work the value of $\bar{k}_{\mathrm{tp}}$ was not estimated.

De la $\mathrm{Cal}^{17}$ demonstrated that the model is less sensitive to the value of the cross-propagation reaction
Table VI. Values of parameters used in the model of VAc homopolymerization

$\begin{array}{lr}\bar{k}_{\mathrm{t}} & 0.29 \times 10^{5} \mathrm{~cm}^{3}(\mathrm{~mol} \mathrm{~s})^{-1} \\ j_{\text {crit }} & 60 \\ m & 3 \\ v_{\mathrm{p}} & 7.5 \times 10^{-15} \mathrm{~cm}^{3} \\ {[\mathrm{VAc}]_{\mathrm{p}}} & 7.115 \times 10^{-3} \mathrm{~mol} \mathrm{~cm}^{-3} \text { of polymer particle } \\ {[\mathrm{VAcc}]_{\mathrm{aq}}} & 0.254 \times 10^{-3} \mathrm{~mol} \mathrm{~cm}^{-3} \text { of aqueous phase } \\ \varphi_{\mathrm{w}}^{\mathrm{aq}} & 0.9765\end{array}$

rate constant of the monomer having a reactivity ratio of less than 1, and the value cannot be estimated accurately. For VAc-MA system, $k_{p_{A B}}$ cannot be estimated. To obtain a more accurate value of $k_{p_{\mathrm{AB}}}, k_{p_{\mathrm{AA}}}$ has to be estimated using the method for parameter estimation in emulsion homopolymerization, and with this value and $r_{\mathrm{A}}$, the value of $k_{p_{\mathrm{AB}}}$ should be calculated. Thus, $k_{\mathrm{a}}, \bar{k}_{\mathrm{d}}$, $k_{1}$, and $k_{p_{\mathrm{AB}}}$ became adjustable parameters of the model.

Table $\mathrm{V}$ shows the results obtained using different initial guesses. It can be seen that $k_{p_{\mathbf{B A}}}$ was well estimated irrespective of the initial guess. However, $k_{\mathrm{a}}, \bar{k}_{\mathrm{d}}$, and $k_{1}$ were affected by significant error. This was thought to be due to the insensitivity of the model to these parameters. Figure 2 shows that the radical absorptiondesorption process contributes to the formation of $N_{1}$ particles, which are the main loci of polymerization, less than the homogeneous nucleation, and the model is insensitive to the corresponding parameters, $k_{\mathrm{a}}$ and $\bar{k}_{\mathrm{d}}$. Figure 3 shows change in the average number of radicals per particle, $\bar{n}$, with polymerization time at the initial stage. These curves sharply increase until the homogeneous nucleation stops and then gradually increase to reach a plateau. The variation of steady value of $\bar{n}$ with changing initiator concentration is fairly small. Therefore, the contribution of the radical formation from the initiator to the total conversion of monomers cannot be exactly estimated.

\section{Homopolymerization of $V A C$}

In the $\operatorname{VAc}(A)-\operatorname{VPi}(B)$ system, the reactivity ratio of VAc, $r_{\mathrm{A}}$ is less than 1 . Therefore, $k_{p_{\mathrm{AB}}}$ had to be calculated by using $k_{p_{\mathrm{AA}}}$ estimated from the VAc homopolymerization data. Considering VAc has relatively high water solubility and transfer rate coefficient, the zero-one assumption $(\bar{n}<0.5)$ should be applicable to the VAc homopolymerization system. However, the size of seed particles was actually relatively large $(\sim 140 \mathrm{~nm})$, and the particles would contain more than one radical at a time. Hence, $\bar{n}>0.5$ system was applied. Table VI presents the values of parameters used in the model.

Table VII shows the results of the parameter estimation and Figures $4-6$ show the experimental results are the value simulated with the estimated parameters. Compar- 
Table VII. Estimated $k_{\mathrm{a}}, \bar{k}_{\mathrm{d}}, k_{\mathrm{l}}$, and $k_{\mathrm{p}}$ in VAc homopolymerization system

\begin{tabular}{|c|c|c|c|c|}
\hline$k_{\mathrm{a}} \times 10^{-12}$ & $\bar{k}_{\mathrm{d}} \times 10^{7}$ & $k_{1} \times 10^{5}$ & $k_{\mathrm{p}} \times 10^{-7}$ & $\mathrm{SD}^{\mathrm{a}}$ \\
\hline 0.7351 & 0.8722 & 0.7117 & 0.9327 & $6.31 \times 10^{-3}$ \\
\hline
\end{tabular}

${ }^{\text {a }} \mathrm{SD}$, sum of squares of differences.

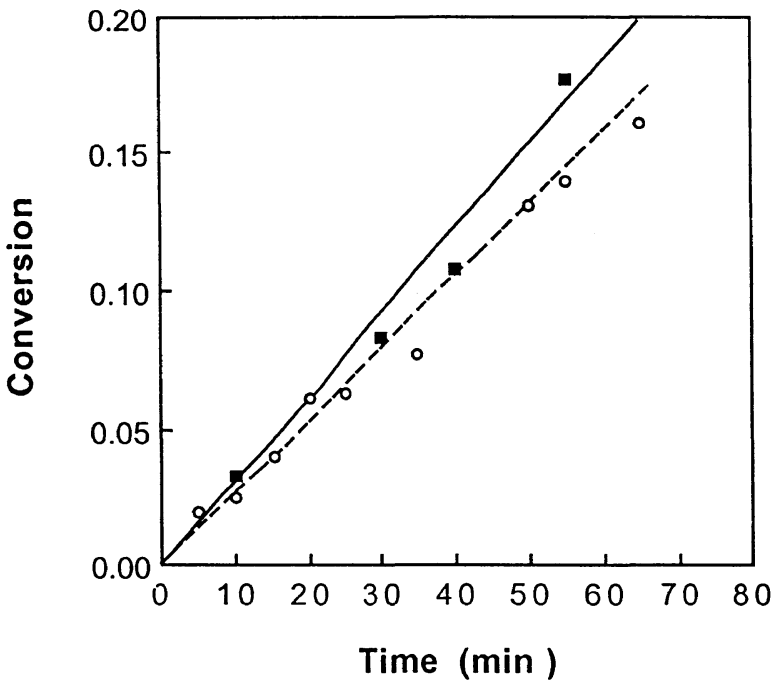

Figure 4. Comparison of simulated and experimental conversions of VAc homopolymerization, $[\mathrm{I}]=7 \times 10^{-5} \mathrm{~mol} \mathrm{~cm}{ }^{-3}$ of water; points, experimental data; lines, simulated values. ( - and $\square$ ), $N_{\mathrm{T} 0}=6 \times 10^{11}$ particles $\mathrm{cm}^{-3}$ of water; $(---$ and $\bigcirc), N_{\mathrm{T} 0}=3 \times 10^{11}$ particles $\mathrm{cm}^{-3}$ of water.

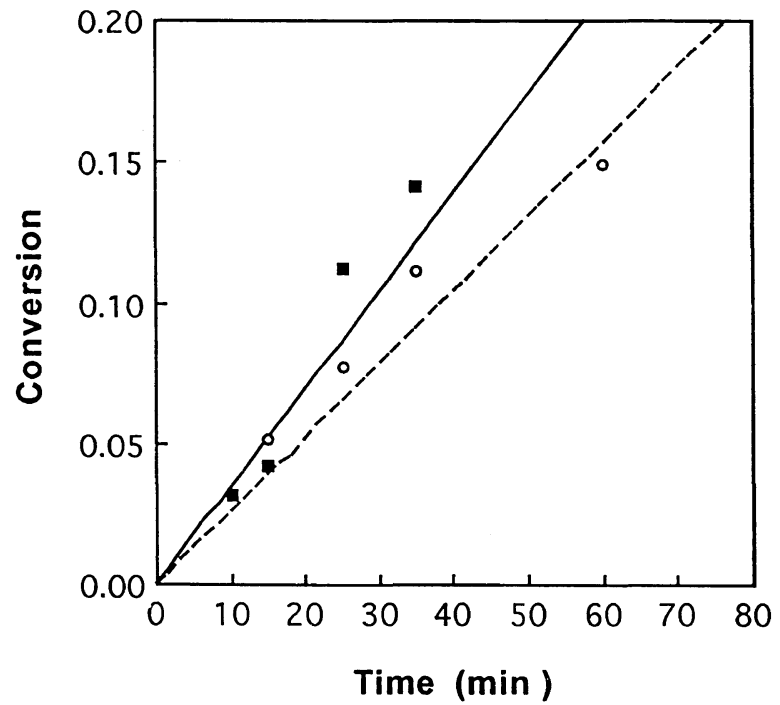

Figure 5. Comparison of simulated and experimental conversions of VAc homopolymerization. [I] $=5 \times 10^{-5} \mathrm{~mol} \mathrm{~cm}^{-3}$ of water; points, experimental data; lines, simulated values. ( - and $\square), N_{\mathrm{T} 0}=9 \times 10^{11}$ particles $\mathrm{cm}^{-3}$ of water; $(---$ and $O), N_{\mathrm{T} 0}=3 \times 10^{11}$ particles $\mathrm{cm}^{-3}$ of water.

ison of the experimental and simulated results reveals good agreement between them to some extent.

\section{Copolymerization of $V A c$ and $V P i$}

Table VIII presents the value of parameters in the model. The termination rate coefficients could not be estimated in this work, and this led us to assume these values as arbitrary but reasonable.

Since the VPi monomer has sufficiently low solubility

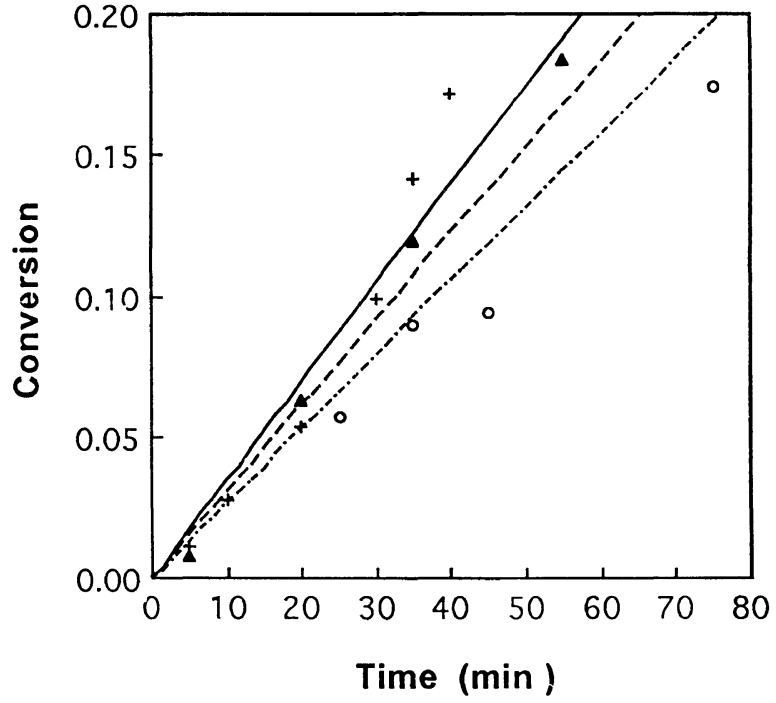

Figure 6. Comparison of simulated and experimental conversions of VAc homopolymerization. [I] $=3 \times 10^{-5} \mathrm{~mol} \mathrm{~cm}^{-3}$ of water; points, experimental data; lines, simulated values. $(-$ and +$), N_{\mathrm{T} 0}=9 \times 10^{11}$ particles $\mathrm{cm}^{-3}$ of water; $(---$ and $\mathbf{\Delta}), N_{\mathrm{T} 0}=6 \times 10^{11}$ particles $\mathrm{cm}^{-3}$ of water; $(---$ and $\bigcirc), N_{\mathrm{T} 0}=3 \times 10^{11}$ particles $\mathrm{cm}^{-3}$ of water.

Table VIII. Values of parameters used in the model of VAc-VPi copolymerization

$\begin{array}{lrlr}k_{t_{\mathrm{AA}}} & 0.29 \times 10^{11} \mathrm{~cm}^{3}(\mathrm{~mol} \cdot \mathrm{s})^{-1} & k_{t_{\mathrm{BB}}} & 0.5 \times 10^{10} \mathrm{~cm}^{3}(\mathrm{~mol} \cdot \mathrm{s})^{-1} \\ r_{\mathrm{A}} & 0.85^{\mathrm{a}} & r_{\mathrm{B}} & 1.1^{\mathrm{a}} \\ j_{\text {crit }} & 60 & m & 3 \\ v_{\mathrm{p}} & 1.63 \times 10^{-14} \mathrm{~cm}^{3} & & \\ m_{\text {Aqp }} & 28 & m_{\text {Aqd }} & 42.5 \\ m_{\mathrm{Bdp}} & 0.5 & m_{\text {wqd }} & 0.01\end{array}$

${ }^{\mathrm{a}}$ From ref 21

Table IX. Estimated $k_{\mathrm{a}}, \bar{k}_{\mathrm{d}}, k_{\mathrm{l}}$, and $k_{p_{\mathrm{BA}}}$ in the VAc-VPi copolymerization system

\begin{tabular}{|c|c|c|c|c|}
\hline$k_{\mathrm{a}} \times 10^{-11}$ & $\bar{k}_{\mathrm{d}} \times 10^{4}$ & $k_{1} \times 10^{9}$ & $k_{p_{\mathrm{BA}}} \times 10^{-7}$ & $\mathrm{SD}^{\mathrm{a}}$ \\
\hline 0.2679 & 0.2973 & 0.1858 & 2.4655 & $6.25 \times 10^{-3}$ \\
\hline
\end{tabular}

a $\mathrm{SD}$, sum of squares of differences.

in water, it was assumed that $[\mathrm{VPi}]_{\mathrm{aq}}$ was equal to zero and in monomer droplets, and water was dissolved in VAc species only. The concentrations of monomers in different phases were calculated using partition coefficients given in Table VIII and the following equations:

$$
\begin{gathered}
\varphi_{\mathrm{A}}^{\mathrm{p}}+\varphi_{\mathrm{B}}^{\mathrm{p}}+\varphi_{\mathrm{pol}}^{\mathrm{p}}=1 \\
\varphi_{\mathrm{A}}^{\mathrm{aq}}+\varphi_{\mathrm{pol}}^{\mathrm{aq}}=1 \\
\varphi_{\mathrm{A}}^{\mathrm{d}}+\varphi_{\mathrm{B}}^{\mathrm{d}}+\varphi_{\mathrm{w}}^{\mathrm{d}}=1 \\
\varphi_{\mathrm{A}}^{\mathrm{p}} V_{\mathrm{p}}+\varphi^{\mathrm{aq}} V_{\mathrm{aq}}+\varphi_{\mathrm{A}}^{\mathrm{d}} V_{\mathrm{d}}=V_{\mathrm{A}} \\
\varphi_{\mathrm{B}}^{\mathrm{p}} V_{\mathrm{p}} \quad+\varphi_{\mathrm{B}}^{\mathrm{d}} V_{\mathrm{d}}=V_{\mathrm{B}} \\
\varphi_{\mathrm{w}}^{\mathrm{aq}} V_{\mathrm{aq}}+\varphi_{\mathrm{w}}^{\mathrm{d}} V_{\mathrm{d}}=V_{\mathrm{w}} \\
\varphi_{\mathrm{pol}}^{\mathrm{d}} V_{\mathrm{p}}=V_{\mathrm{pol}}
\end{gathered}
$$

where $\varphi_{i}^{j}$ is the volume fraction of component $i$ in $j$ phase; $V_{\mathrm{p}}, V_{\mathrm{aq}}$, and $V_{\mathrm{d}}$ are the volumes of the monomer swollen polymer particle, aqueous phase, and the monomer droplets, respectively; $V_{\mathrm{A}}, V_{\mathrm{B}}, V_{\mathrm{w}}$, and $V_{\mathrm{pol}}$ are the volumes of VAc, VPi, water, and copolymer, respectively.

Table IX shows the results of the parameter estimation

Polym. J., Vol. 28, No. 10, 1996 


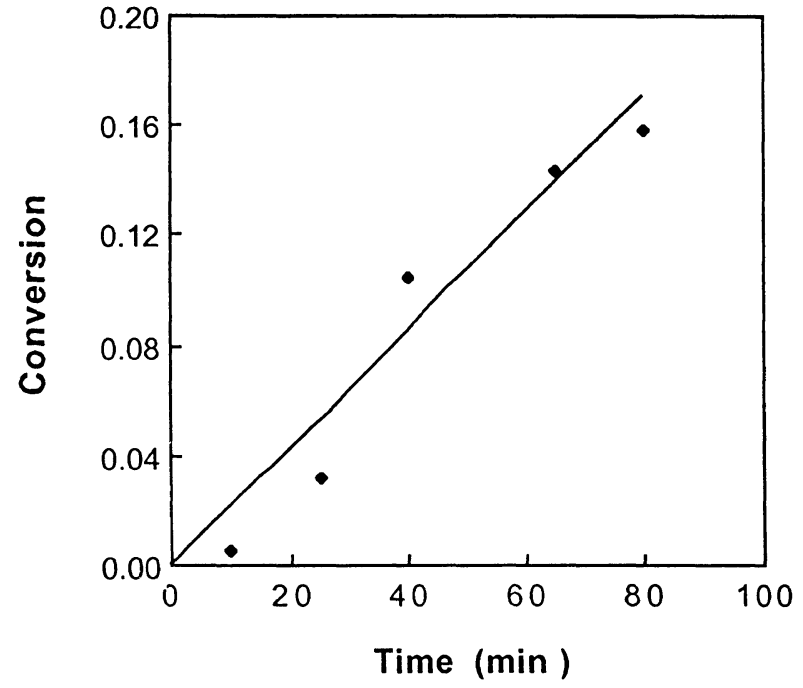

Figure 7. Comparison of simulated and experimental conversions of VAc-VPi copolymerization. $[\mathrm{I}]=1 \times 10^{-4} \mathrm{~mol} \mathrm{~cm}^{-3}$ of water; $N_{\mathrm{T} 0}=$ $1.5 \times 10^{11}$ particles $\mathrm{cm}^{-3}$ of water; points, experimental data; lines, simulated values.

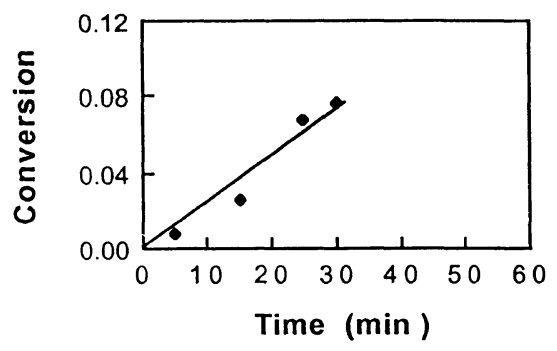

(a)

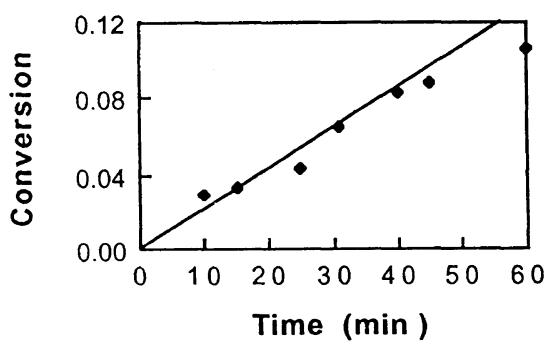

(b)

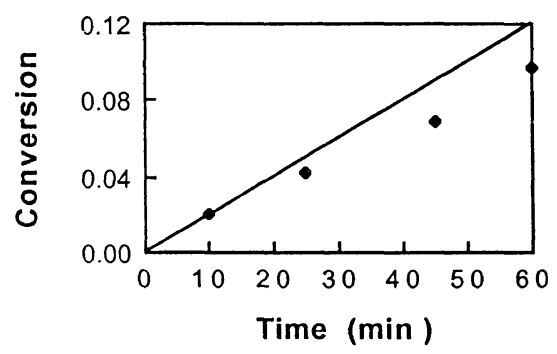

(c)

Figure 8. Comparison of simulated and experimental conversions of VAc-VPi copolymerization. $[\mathrm{I}]=7 \times 10^{-5} \mathrm{~mol} \mathrm{~cm}^{-3}$ of water; points, experimental data; lines, simulated values. $N_{\text {T0 }}$ (particles $\mathrm{cm}^{-3}$ of water): (a) $3.0 \times 10^{11}$; (b) $1.5 \times 10^{11}$; (c) $8.0 \times 10^{10}$.

and Figures 7-9 show the experimental results and the values simulated using the estimated parameters. A comparison of the experimental and simulated results reveals good agreement.

Using these estimated parameters, the effect of

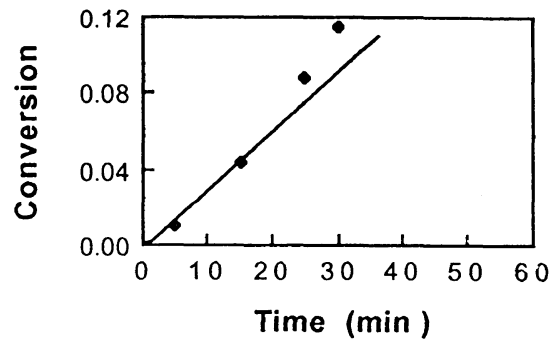

(a)

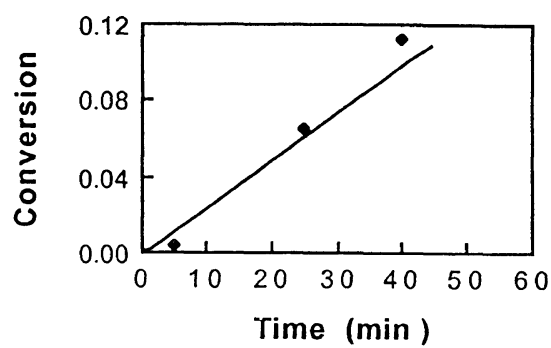

(b)

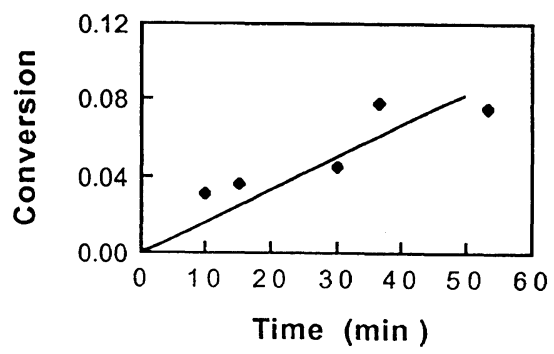

(c)

Figure 9. Comparison of simulated and experimental conversions of VAc-VPi copolymerization. [I] $=3 \times 10^{-5} \mathrm{~mol} \mathrm{~cm}^{-3}$ of water; points, experimental data; lines, simulated values. $N_{\text {To }}$ (particles $\mathrm{cm}^{-3}$ of water): (a) $6.0 \times 10^{11}$; (b) $3.0 \times 10^{11}$; (c) $1.5 \times 10^{11}$.

monomer feed ratio on the cumulative copolymer composition was investigated. In the emulsion polymerization system, the monomers are partitioned in different phases so that the concentrations of monomers in polymer particles, the main loci of polymerization, are different from those charged initially and hence, it was supposed that the copolymer composition varies over a wide range in this system.

Figure 10 shows the ${ }^{13} \mathrm{C}$ NMR spectrum of P(VAc$\mathrm{VPi}$ ) copolymer. By comparing the carbonyl carbon peak of VAc at $170 \mathrm{ppm}$ with the carbonyl carbon peak of VPi at $177 \mathrm{ppm}$, the copolymer composition was determined.

Figure 11 shows the effect of the monomer mole ratio on the cumulative copolymer composition along with the prediction of the model using the estimated parameters. The predicted values of the copolymer composition considering the partitions of monomers in the different phases are also presented.

Because of the close value of the reactivity ratios of two monomers, i.e., VAc and VPi, the copolymer composition was almost the same as the monomer feed ratio, but there was a little difference in the copolymer composition when the partition of monomers was considered. It is thus confirmed that correct determination of the values of partition coefficients is required to predict copolymer composition accurately. 


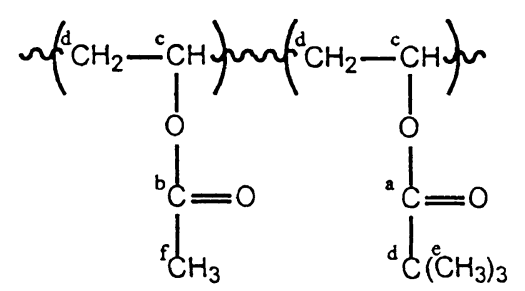

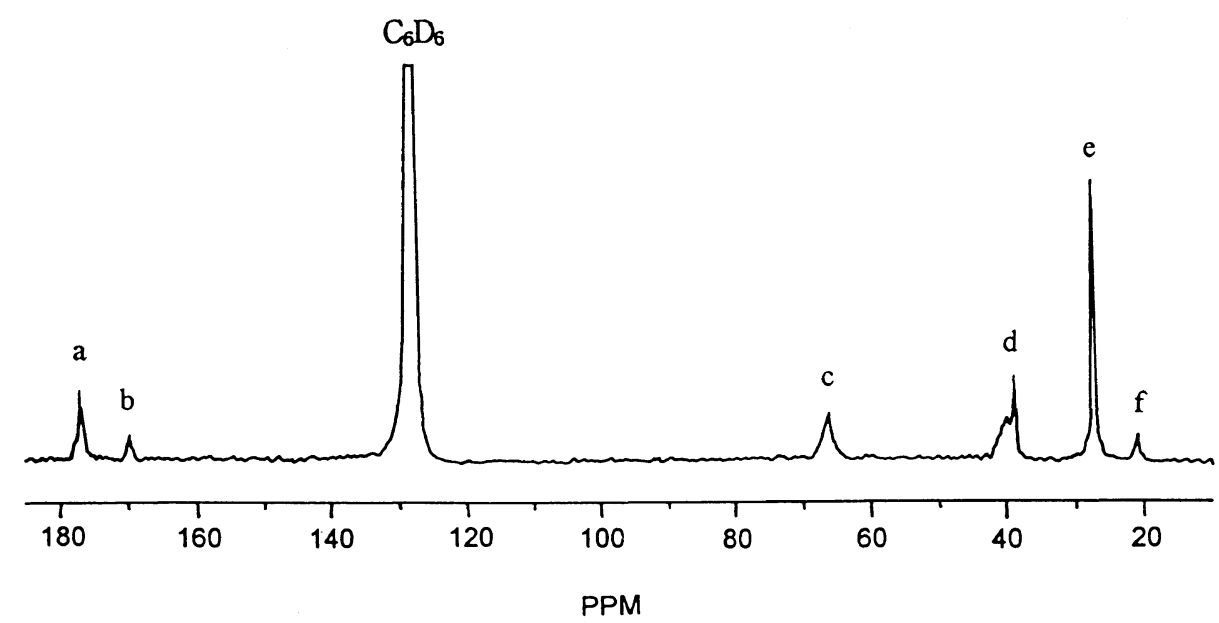

Figure 10. ${ }^{13} \mathrm{C}$ NMR spectrum of $\mathrm{P}(\mathrm{VAc}-\mathrm{VPi})$ copolymer.

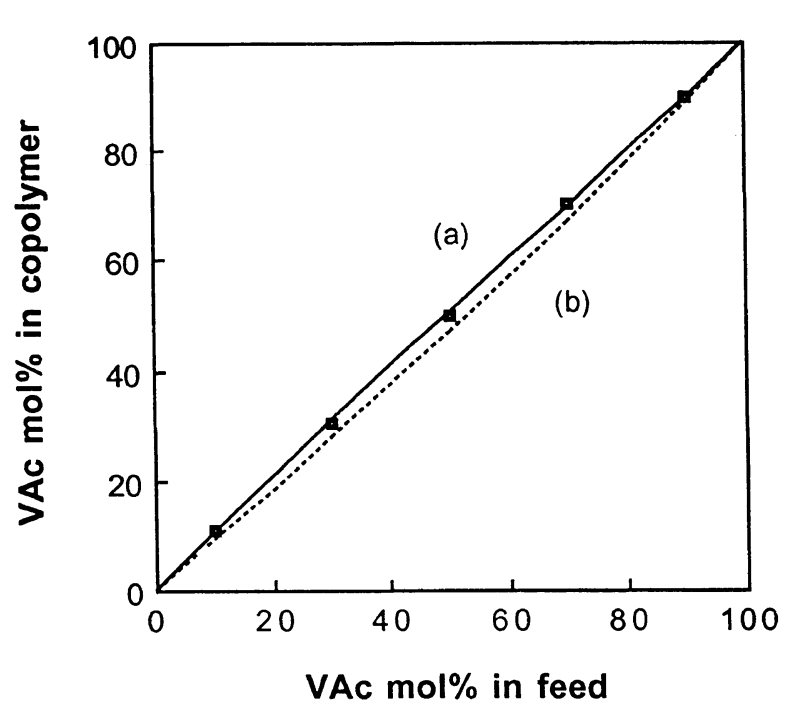

Figure 11. Comparison of experimental and simulated copolymer compositions as a function of monomer feed composition (VAc molar fraction): Points, experimental data; lines, simulated results (a) taking or (b) not taking into account of partitions of monomers in different phases.

\section{CONCLUSIONS}

The parameters in the emulsion copolymerization of VAc and VPi were estimated by the non-linear regression method. A model was developed considering homogeneous nucleation, aqueous phase polymerization, and probability of the presence of particles having more than two radicals. In checking the validity of this model and method of parameters estimation using VAc-MA copolymerization system, the absorption rate coefficient, $k_{\mathrm{a}}$, desorption rate coefficient, $\bar{k}_{\mathrm{d}}$ and termination rate coefficient, $\bar{k}_{\mathrm{tp}}$, were correlated to each other, but the model was insensitive to the values of $k_{\mathrm{a}}, \bar{k}_{\mathrm{d}}$, and rate coefficient for the radical generation from the initiator, $k_{1}$. Therefore, these parameters could not be exactly estimated in this system. However, the propagation rate constant could be accurately estimated. In the homopolymerization and copolymerization of VAc and VPi, the conversion simulated with the estimated parameters reasonably agreed with the experimental data. In the experiments with the initial monomer feed ratio, the experimental copolymer composition data agreed well with simulated values, considering the partitions of the monomers in different phases, so that it is suggested that the partition coefficient should be determined accurately to predict the copolymer composition correctly.

Acknowledgments. The authors gratefully acknowledge financial support from Engineering Education and Research Foundation, Seoul National University in 1993 for this work.

\section{REFERENCES}

1. F. L. Martin, in "Encyclopedia of Polymer Science and Technology," Vol. 17, H. F. Mark, N. M. Bikales, C. G. Overberger, G. Menges, and J. I. Kroschwitz, Ed., John Wiley \& Sons, New York, N.Y., 1985, pp 167-180 and p 188.

2. K. Toyoshima, in "Polyvinyl Alcohol," C. A. Finch, Ed., John Wiley \& Sons, New York, N.Y., 1973, pp 339-388.

3. I. Sakurada, "Polyvinyl Alcohol Fibers," Marcel Dekker, New York, N.Y., 1985, pp 3-9 and pp 361-386.

4. M. Masuda, in "Polyvinyl Alcohol-Development," C. A. Finch, Ed., John Wiley \& Sons, New York, N.Y., 1991, pp 403-422 and $\mathrm{p} 711$.

5. T. Yamamoto, S. Yoda, O. Sangen, R. Fukae, and M. Kamachi, Polym. J., 21, 1053 (1989).

6. R. Fukae, K. Kawakami, T. Yamamoto, O. Sangen, T. Kako, and M. Kamachi, Polym. J., 27, 1257 (1995).

7. T. Yamamoto, R. Fukae, T. Saso, O. Sangen, M. Kamachi, T. Sato, and Y. Fukunishi, Polym. J., 24, 115 (1992).

8. B. C. Y. Whang, D. H. Napper, M. J. Ballard, R. G. Gilbert, and G. Lichiti, J. Chem. Soc., Faraday Trans. 1, 78, 1117 (1982).

9. R. G. Gilbert and D. H. Napper, J. Macromol. Sci. Rev. 
Macromol. Chem. Phys., C23, 127 (1983).

10. I. A. Maxwell, D. H. Napper, and R. G. Gilbert, J. Chem. Soc., Faraday Trans. 1, 83, 1449 (1987).

11. G. Lichiti, B. S. Hawkett, R. G. Gilbert, D. H. Napper, and D. F. Sangster, J. Polym. Sci., Polym. Chem. Ed., 19, 925 (1981).

12. M. Nomura, Makromol. Chem. Suppl., 10/11, 25 (1985).

13. M. Nomura, J. Appl. Polym. Sci., 37, 1029 (1987).

14. J. M. Asua, M. E. Adams, and E. D. Sudol, J. Appl. Polym. Sci., 39, 1183 (1990).

15. M. J. Barandiaran, M. E. Adams, J. C. de la Cal, E. D. Sudol, and J. M. Asua, J. Appl. Polym. Sci., 45, 2187 (1992).

16. J. C. de la Cal, M. E. Adams, and J. M. Asua, Makromol. Chem.
Macromol. Symp., 35/36, 23 (1990).

17. J. C. de la Cal, J. Polym. Sci., Polym. Chem. Ed., 29, 155 (1991).

18. A. Contantinides, "Applied Numerical Method with Personal Computers," McGraw-Hill, New York, N.Y., 1987, p 528.

19. F. K. Hansen and J. Ugelstad, in "Emulsion Polymerization," I. Piirma, Ed., Academic Press, New York, N.Y., 1982, p 51.

20. C. W. Gear, "Numerical Initial Value Problems in Ordinary Differential Equations," Prentice-Hall, Englewood Cliffs, NJ, 1971, p 136.

21. D. G. Watts, H. N. Linssen, and J. Shrijver, J. Polym. Sci., Polym. Chem. Ed., 18, 1285 (1980). 